\title{
Pemanfaatan Private Cloud Storage Berbasis Infrastructure As A Service (IAAS)
}

\author{
Sudetlin ${ }^{1}$, Novi Dian Natasha ${ }^{2}$,Ucuk Darusalam ${ }^{3}$ \\ ${ }^{1}$ sudetlin@gmail.com, ${ }^{2}$ ivanovic77@yahoo.com, ${ }^{3}$ ucuk.darusalam@civitas.ac.id
}

\section{Program Studi Teknik Informatika, Fakultas Teknologi Komunikasi dan Informatika, Universitas Nasional}

\begin{abstract}
Data and information are important and valuable in a company or institution, therefore the data is very important to guard or managed very well, especially in company or companies that are in the development stage, of course things it needs to be done. Private Cloud Storage is a service that integrates to improve data security and speed up data access. In this st udy use OwnCloud as free data sharing and provides good security, Proxmox virtualization platform as Cloud Computing Infrastructure-As-A Service (IAAS) service that can provide an Open source Platform infrastructure and Redundant Array of Independent Disk (RAID) to increase disk capacity and speed up data access. With the implementation of Redundant Array of Independent Disk (RAID) on Infrastructure as a Service (IAAS) obtained maximum results on the use of Ethernet0 90.75 is Mbps, $9.65 \%$ used memory, and CPU loading up to $36 \%$ when uploading 559MB File 11 users almost simultaneously.
\end{abstract}

Abstract- Data dan informasi merupakan hal yang penting dan berharga dalam suatu lembaga atau instansi, oleh $k$ arena itu data sangat penting untuk menjaga dan mengelola data dengan baik, apalagi di instansi atau perusahaan yang sedang dalam tahap perkembangan, tentunya hal tersebut perlu dilakukan. Peran private cloud storage merupakan layanan yang terintegrasi untuk meningkatkan keamanan dan mempercepat akses data. Pada penelitian ini digunakan OwnCloud sebagai sharing data gratis dan menyediakan pengamanan yang baik, paltform virtualisasi Proxmox sebagai pelayanan Infrastructure-As-A-Service (IAAS) Cloud Computing yang dapat menyediakan sebuah infrastructure Paltform yang bersifat opensource dan Redundant Array of Independent Disk (RAID) untuk menambah kapasistas disk dan mempercepat pengaksesan data. Dengan diterapk annya Redundant Array of Independent Disk (RAID) pada Infrastructure as a Service (IAAS) didapatkan hasil maksimum pada penggunaan sisi Ethernet0 90.75 Mbps, Memory ter pakai 9.65\%, dan pada CPU loading hingga 36\% saat upload data File 559MB dengan 11 user secara hampir bersamaan.

Kata Kunci-Private Cloud Storage, IAAS, Server Proxmox, RAIDO

\section{PENDAHULUAN}

Cloud computing (komputasi awan) merupakan gabungan pemanfaatan teknologi komputer (komputasi) dalam suatu jaringan dengan pengembangan berbas is internet (awan) yang mempunyai fungsi untuk menjalankan program atau aplikasi melalui komputer - komputer yang terkoneksi pada waktu yang sama. Teknologi komputer berbasis sistem Cloud ini merupakan sebuah teknologi yang menjadikan internet sebagai pusat server untuk mengelola data dan juga aplikasi pengguna. Teknologi ini mengizinkan para pengguna untuk menjalankan program tanpa instalasi dan mengizinkan pengguna untuk mengakses data pribadi mereka melalui komputer dengan akses internet.

Bagi setiap pengguna data tentunya merupakan hal yang penting dan sensitif, karenanya hal ini menimbulkan kehawatiran pengguna. Dengan memanfaatkan Private Cloud Storage yang menyediakan lingkungan khusus dan terlindungi di belakang firewall organisasi dan menawarkan tingkat keamanan dan kontrol yang tinggi [8,9] dengan metode Infrastructure as a Service (IAAS) yang sumberdaya komputasi meliputi server, jaringan, storage dan ruang data center secara pay-per-use.

Layanan private cloud sesuai untuk penyimpanan data yang membutuhkan keamanan lebih baik, kustomisasi dan kontrol lebih besar atas data tersebut [3,6]. Sebagai model mewujudkan integrasi sumber daya manufaktur dan berbagi[10,11], dengan menerapkan Redundant Array of Independent Disk 0 (RAID0) pada data Storage Infrastructure as a Service (IAAS) dapat menambah kapasistas, me mpercepat pengakses an data dengan kemampuan baca-tulis pada drive sistem Cloud Computing menjadi meningkat [7], dengan peningkatannya kemampuan drive dapat memudahkan konsumen menyebarkan data dan menjalankan perangkat lunak secara bebas, dapat mencakup sistem operasi dan aplikasi menjadi meningkat[3].

Dengan virtualisasi proxmox sebagai layanan platform Infrastructure-As-A-Service (IAAS) yang dapat menyediakan sebuah infrastructure plaform yang handal dan observium sebagai tools monitoring Network dan server berbasis auto discovering yang dapat mengumpulkan semua data server melalui SNMP, yang nantinya akan ditampilkan melalui web interface sebagai media untuk melakukan logging dan graphing.

Adapun penelitian terkait peroleh kinerja memory 66\%, cpu 64\%, dan network 95.50M Bits/s dengan RAM 2GB[1]. Penggunaan memory $47.7 \%$, cpu $5.0 \%$ [2] pada kedua penelitian ini tidak mengadopsi RAID0.

\section{A. Cloud Computing}

\section{KAJIAN PUSTAKA}

Onno W Purbo [13] menyebutkan dalam Ibrahim, M. \& Kusnawi, (2013) bahwa Cloud Computing adalah sebuah model ko mputasi/computing, dimana sumber daya (hardware) processor/computing power, storage, network, dan software menjadi abstrak dan diberikan sebagai layanan di jaringan/internet menggunakan pola akses remote. Model billing dari layanan ini umumnya mirip dengan modem layanan publik. Atribut penting cloud computing salah 
satunya adalah ketersediaan (on-demand) sesuai kebutuhkan, mudah untuk di kontrol, dinamik dan skalabilitas yang hamp ir tanpa limit [12].

Cloud Computing berdasarkan tipe service-nya terbagi menjadi tiga [16] Yaitu: 1) SaaS (Software as a Service), merupakan bagian dari cloud computing yang terdiri aplikasi untuk digunakan oleh end user. Aplikasi biasanya disesuaikan dengan kebutuhan end user. 2) Paas (Platform as a Service) merupakan bagian cloud computing yang terdiri aplikasiaplikasi dasar contohnya sistem operasi, bahas a pemrograman dasar, database dan web server. 3) IaaS (Infrastruture as a Service) merupakan bagian cloud computing yang terdiri dari bagian fisik (hardisk, memory, dll). Pada umumnya menggunakan teknologi virtual mechine, sumber daya yang ada digunakan secara bersama-sama [16].

\section{B. Karakteristing Cloud Computing}

Menurut Nasional Institute of Standards and Technology (NIST), terdapat lima karakteristik komputasi awan [14] yang antara lain adalah :

\section{1) SelfService}

Cloud consumer bisa mengkonfigurasikan secara mandiri layanan yang ingin dipakai melalui sebuah sistem, tanpa perlu interaksi manusia dengan pihak cloud provider

\section{2) Resource Pooling}

Penyedia layanan cloud, memberikan layanan melalui sumberdaya yang dikelo mpokkan di satu atau berbagai lokasi data center yang terdiri dari sejumlah server dengan mekanisme multi-tenant.

3) BroadNetwork Access

Kapabilitas layanan yang tersedia lewat jaringan broadband bisa diakses oleh berbagai perangkat, seperti laptop, smartphone, tablet, workstation, dan sebagainya.

\section{4) Measured Service}

Tersedia layanan untuk mengoptimalisasi dan memonitor layanan yang dipakai secara otomatis. Dengan monitoring sistem ini, kita bis a melihat berapa resources ko mputasi yang telah dipakai, seperti : bandwidth, storage, processing, ju mlah pengguna aktif, dan sebagainya.

\section{5) Rapid Elasticity}

Kapabilitas dari layanan cloud provider bisa dipakai oleh cloud consumer secara dinamis berdasarkan kebutuhan.

\section{Perkembangan Model Cloud Computing}

Cloud computing berkembang dengan sangat cepat, dibangun bersama-sama komunitas dan kelompok open source. Berikut ini adalah model pengembangan Cloud Computing [15] yang antara lain:

1. Public Cloud merupakan model pengembangan pertama adalah public atau external cloud. Ini adalah cloud computing dalam bentuk tradisional di mana sumber daya diatur secara dinamis melalui internet via aplikasi web dan web service

2. Private Cloud atau internal cloud merupakan layanan cloud computing yang di tawarkan untuk jaringan privat. Produknya antara lain otomatisasi virtualisasi. Produk ini menawarkan kemampuan untuk menjadi host aplikasi atau mesin virtual di host perusahaan.

3. Hybrid Cloud, istilah Hybrid digunakan untuk menjelaskan penggabungan lebih dari satu tipe cloud, misalnya public cloud dengan private, internal atau external. Bisa juga mengacu pada pengelompokan cloud virtualisasi di server yang bekerja dengan hardware fisik .

4. Community Cloud adalah cloud yang didirikan oleh beberapa organisasi yang membutuhkan beberapa insfrastruktur dan pers yaratan yang sama, sehingga me reka bisa saling berbagi sumber daya dan manfaatkan keuntungan cloud computing, karena biaya untuk cloud computing ini ditanggung oleh beberapa pihak dan bukan oleh public maka opsi ini lebih mahal dibandingkan opsi public, tapi opsi ini akan membuat privasi data lebih baik

\section{METODE PENELITIAN}

Cloud Storage media penyimpanan data yang dapat diakses oleh para penggunanya lewat jaringan internet. Misalnya seorang karyawan menyimpan tugas, dokumen, dll. untuk memudahkannya bekerja dimana saja, maka akan menyimpannya di cloud storage. Saat data disimpan secara 'cloud', data-data tersebut dapat dengan mudah diakses lewat jaringan internet, Secara umum, jaringan private cloud yang dirancang dan diimplementasikan, seperti pada Gambar 1, disajikan pada gambar tersebut merupakan tahap perancangan dan implementasi dilaku kan instalasi Pro xmox VE, yang akan digunakan sebagaiplatform.

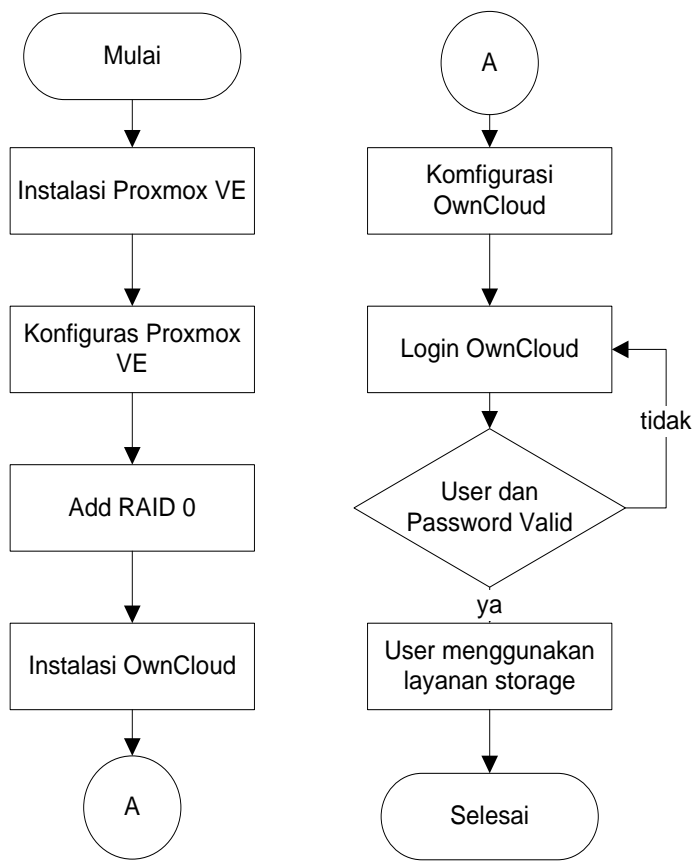

Gambar 1. Tahap perancangan dan implementasi

Redundant Array of Independent Disk (RAID) untuk mengabungkan 2 disk. OwnCloud sebagai sharing data, dengan membuka Web browser dan mengakses Owncloud yang akan menampilkan halaman login, user harus mengisi form username dan password untuk dapat mendapatkan akses masuk, tetapi apabila user belum terdaftar maka user harus registrasi terlebih dahulu melalui admin dan login kembali. Setelah masuk ke halaman web, user dapat menggunakan layanan storage yang disediakan untuk sharing data dan sinkronisasi data. 


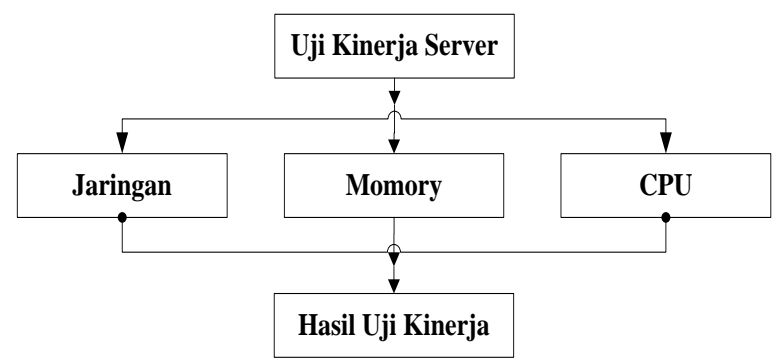

Gambar 2. Tahap pengujian Server

Pada Gambar 2 disajikan diagram tahap Pengujian Server dengan cara upload data secara hampir bersamaan pada server, untuk menunjukan tingkat penggunaan sumber daya perangkat keras tertentu seperti penggunaan Jaringan ethenet $0, \mathrm{CPU}$ dan memori. Tujuannya adalah melihat tingkat kesibukan resource server saat di akses user.

\section{Desain Topologi Jaringan}

\section{HASIL DAN PEMBAHASAN}

Jaringan tulang punggung (backbone) dari sistem yang akan diujikan dalam penelitian ini, karena itu kebutuhan akan arsitektur/desain jaringan harus memenuhi kebutuhan layanan dan karakteristik dari layanan yang akan dijalankan diatasnya. Desain topologi jaringan yang digunakan untuk pengujian kinerja virtualisasi server menggunakan Proxmox ini dapat dilihat pada Gambar 3.

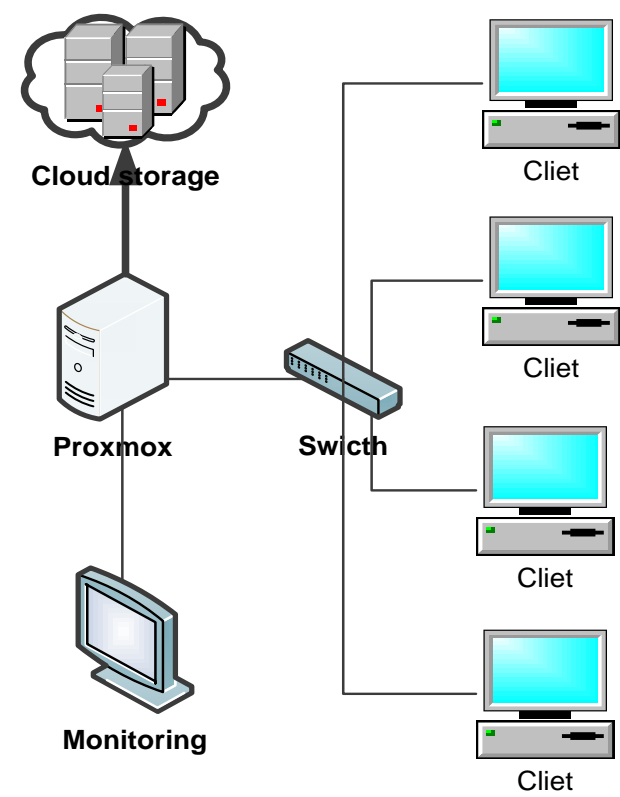

Gambar 3. Desain Topologi Jaringan Pengujian

Gambar 3 diatas adalah topologi perancangan komponen jaringan host dengan host host yang lain terhubung melalui switch, server fisik dan virtual dapat mengakses internet melalui koneksi yang di-sharing oleh host client. Semua host yang terkoneksi di jaringan ini menggunakan 1 kelas alamat IP.

\section{Spesifikasi Perangkat Keras Dan Lunak}

Pada Tabel 1 disajikan spesifikasi hardware yang dibutuhkan untuk menjalankan system pada proxmox dan system OwnCloud.
Tabel 1.

Spesifikasi Perangkat( Hardware )

\begin{tabular}{|c|c|c|}
\hline Hardware & Proxmox & VM Own cloud \\
\hline CPU & $\begin{array}{l}\text { Intel® } \text { Core }^{\mathrm{TM}} \\
\text { i5-2400@3.10GHz } \\
3.40 \mathrm{GHz} \text { (1 socket) }\end{array}$ & $\begin{array}{l}\text { Intel® } \text { Core }^{\mathrm{TM}} \\
\text { i5-2400@3.10GHz } \\
3.40 \mathrm{GHz} \text { (1 socket) }\end{array}$ \\
\hline RAM & 4GB & 3GB \\
\hline Hardisk & 750GB & 400GB \\
\hline Switch & \multicolumn{2}{|c|}{1 D-LINK DES-1024D } \\
\hline $\begin{array}{l}\text { Kabel } \\
\text { UTP }\end{array}$ & \multicolumn{2}{|l|}{ 100.0 MBps } \\
\hline
\end{tabular}

Tabel 2.

Spesifikasi Perangkat Lunak(Software)

\begin{tabular}{ll}
\hline Sofiwere & Spesifikasi Softwere \\
Proxmox VE 5.0 & $\begin{array}{l}\text { Karnel Linux 4.10.17-2-pve\#1 SMP } \\
\text { PVE 4.10.17-19 }\end{array}$ \\
\hline Owncloud & Owncloud 10.0.2.1 \\
\hline Observium & Obeservium
\end{tabular}

Table 2 merupakan spesifikasi perangkat lunak yang dibutuhkan untuk menjalankan sistem. Dengan spesifikasi yang digunakan sesuai dengan standar minimal yang dimiliki perangkat keras.

\section{Konfigurasi Sistem}

Gambar 4. adalah gambar dari hasil konfigurasi IP address yang digunakan untuk Proxmox. IP addres yang penulis Gunakan yaitu 10.42.42.42

\begin{tabular}{rl|} 
Management Interface: & enp0s3 - 08:00:27:c6:65:e0 (e1000) \\
Hostname (FQDN): & sudetlin@pve.com \\
IP Address: & 10.42 .42 .42 \\
Netmask: & 255.255 .255 .0 \\
Gateway: & 10.42 .42 .1 \\
DNS Server: & 10.42 .42 .1
\end{tabular}

Gambar 4. Konfigurasi ip Proxmox

Tahap konfigurasi RAID 0

1. Proses pertama dengan perintah mdadm -create /dev/mdl -level=0 -raiddevices=2 /dev/sda/ dev/sdb.

2. Memberikan nama system dengan perintah mkfs.ext4 / dev/md 1

3. Kemudian membuat grub dengan perintah vgcreate raid0/dev/mdl

4. Cek hasil dengan perintah

lsblk

\begin{tabular}{|c|c|c|c|c|c|c|}
\hline JAME & MAJ:MIN & $\mathrm{RM}$ & SIZE & RO & TYPE & MOUNTPOINT \\
\hline sda & $8: 0$ & $\theta$ & $465.8 \mathrm{G}$ & 0 & disk & \\
\hline - sda 1 & $8: 1$ & $\theta$ & $1907 \mathrm{~K}$ & 0 & part & \\
\hline - sda2 & $8: 2$ & 0 & $465.8 \mathrm{G}$ & $\theta$ & part & \\
\hline Lsda 9 & $8: 9$ & 0 & $8 M$ & $\theta$ & part & \\
\hline $\mathrm{sdb}$ & $8: 16$ & $\theta$ & 232.96 & $\theta$ & disk & \\
\hline F sdb1 & $8: 17$ & $\theta$ & 232.96 & $\theta$ & part & \\
\hline L sdb9 & $8: 25$ & $\theta$ & $8+1$ & $\theta$ & part & \\
\hline$z d \theta$ & $230: 0$ & $\theta$ & $4 \mathrm{G}$ & $\theta$ & disk & [SHAP] \\
\hline
\end{tabular}

Gambar 5. Hasil Konfigurasi 
Pada Gambar 5 adalah gambar hasil dari sintak untuk penambahan disk baru dengan menggunakan Redundant Array of Independent Disk (RAID) pada Infrastruktur as a Service (IAAS).

$$
\text { CPU usage }
$$

$0.05 \%$ of $4 \mathrm{CPU}(\mathrm{s})$

Load average

$0.00,0.02,0.00$

RAM usage $25.63 \%(984.25 \mathrm{MiB}$ of $3.75 \mathrm{GiB})$

HD space(root) $0.22 \%(1.45 \mathrm{GiB}$ of $668.58 \mathrm{GiB})$

Gambar 6. Disk di proxmox

Gambar 6. adalah gambar dari Summary Proxmox hasil dari penambahan disk.

$\begin{array}{ll}\text { Web: } & \text { http://10.42.42.52 } \\ & \text { https://10.42.42.52 } \\ \text { Web shell: } & \text { https://10.42.42.52:12320 } \\ \text { Webmin: } & \text { https://10.42.42.52:12321 } \\ \text { Adminer: } & \text { https://10.42.42.52:12322 } \\ \text { SSH/SFTP: } & \text { root@10.42.42.52 (port 22) }\end{array}$

Gambar 7. Konfigurasi ip Owncloud

Gambar 7. adalah gambar dari hasil konfigurasi IP address yang digunakan untuk VM Owncloud. IP addres yang penulis gunakan yaitu 10.42.42.52.

\section{Pengujian Kinerja}

Pada tahap pengujian ini, diperlihatkan pengukuran dari kinerja Ethernet, Memory, $C P U$, dengan menggunakan perangkat lunak Observium. Pengukuran ini digunakan untuk mengetahui kinerja berdasarkan yang terdapat pada sistem virtual machines OwnCloud.

Pada pengukuran ini, diambil data sebanyak 11 user, kemudian data tersebut diambil untuk mendapatkan hasil yang valid.

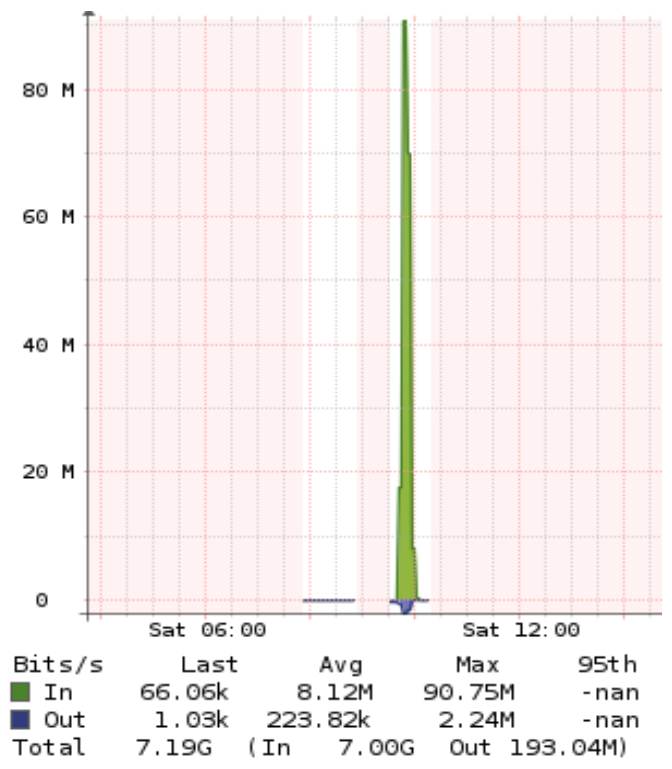

Gambar 8. Trafik pengujian Ethernet0

Tabel 3.

Pengujian Ethernet0

\begin{tabular}{lccc} 
Bits/s & Avg & Last & Max \\
\hline In & $8.12 \mathrm{M}$ & $66.06 \mathrm{k}$ & $90.75 \mathrm{M}$ \\
\hline Out & $223.82 \mathrm{k}$ & $1.03 \mathrm{k}$ & $2.24 \mathrm{M}$ \\
\hline
\end{tabular}

Pada Table 3 ditunjukkan tabel Hasil pengujian pada penggunaan Jaringan Ethernet0 maksimal $90.75 \mathrm{Mbps}$ saat upload data File 559MB dengan 11 user secara hampir bersamaan.

Tabel 4.

Pengujian memory VM

\begin{tabular}{lccc} 
T/U & Size & Used MB & Used\% \\
Physical Memory & $3.22 \mathrm{~GB}$ & 310.78 & 9.65 \\
\hline Virtual & $6.44 \mathrm{~GB}$ & 310.78 & 4.83 \\
\hline Memory buffers & $3.22 \mathrm{~GB}$ & 0.00 & 0.00 \\
\hline Swap space & $3.22 \mathrm{~GB}$ & 0.00 & 0.00 \\
\hline
\end{tabular}

Table 4. diatas adalah tabel Hasil pengujian pada penggunaan memory saat upload data File 559MB dengan 11 user secara hampir bersamaan.

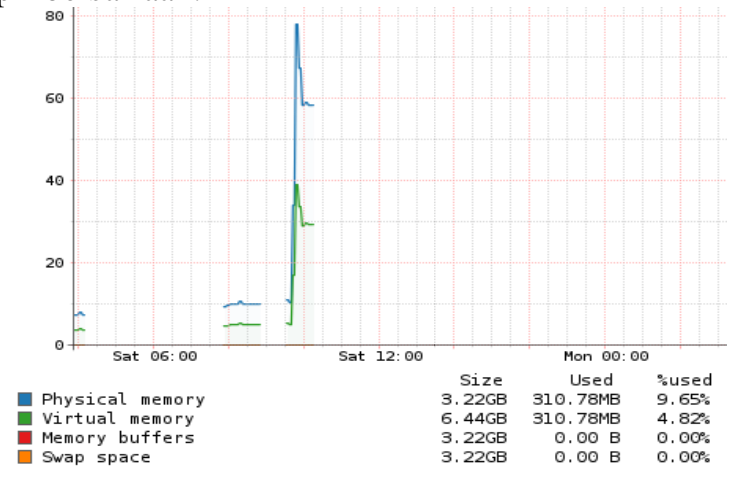

Gambar 9. Trafik pengujian memory VM

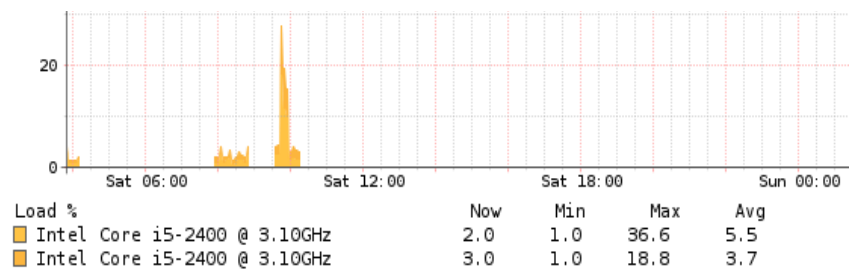

Gambar 10. Trafik pengujian pada CPU VM

Tabel 5.

Pengujian pada CPU VM

$\begin{array}{lccc}\text { Load }(\%) & \text { Min } & \text { Max } & \text { Avg } \\ \text { Intel® Core }{ }^{\mathrm{TM}} \text { i5-2400 } & 1.0 & 36.6 & 5.5 \\ @ 3.10 \mathrm{GHz} 3.40 \mathrm{GHz} & & \end{array}$

Table 5. diatas adalah tabel Hasil pengujian dengan penggunaan maksimal $36.6 \%$ penggunaan CPU saat upload data File 559MB dengan 11 user secara hampir bersamaan. pada pengujian ini penggunaan RAID 0 pada storage cloud dapat meningkatkan performa dibandingkan tadpa RAID.

\section{KESIMPULAN DAN SARAN}

Berdasarkan hasil pengujian didapatkan bahwa virtual mesin Owncloud dapat digunakan sebagai penyedia layanan storage pada Cloud Computing, dengan diterapkannya RAID0 di Disk Infrastructure as a Service (IAAS), Pada Pengujian sisi Ethernet 0 maksimal $90.75 \mathrm{Mbps}$, Memory terpakai $9.65 \%$, dan pada CPU loading maksimal hingga $36.6 \%$ saat upload data File 559MB dengan 11 user secara hampir bersamaan. Pemanfaatan private cloud storage dengan diterapkannya RAID0 dan menggunakan proxmox sebagai virtualisasi server dan jaringan local maka akan mendapatkan banyak keuntungan diataranya adalah pemanfaatan resource yang lebih maksimal, sinkronisasi penyimpanan data secara 
terpusat, mempercepat pengaksesan data, selain itu juga dapat meningkatkan keamanan, dan memudahkan menejemen berkas.

\section{DAFTAR PUSTAKA}

[1] Danang Setiyawan dkk "Implementasi Cloud Computing Menggunakan Model Infrastructure As A Service Untuk Optimalisasi Layanan Data Center" Universitas Gadjah Mada Yogyakarta (2014)

[2] Fitriana Fajrin \& Ahmad Sabiq "Private Cloud Menggunakan Proxmox VE Pada Sistem Informasi Akademik Politeknik Purbaya" 2016

[3] Bahrami M., Singhal M. (2015) "The Role of Cloud Computing Architecture in Big Data". In: Pedrycz W., Chen SM. (eds) Information Granularity, Big Data, and Computational Intelligence. Studies in Big Data, vol 8. pp 275-295, Springer, Cham

[4] Peter Mell \& Timothy Grance. "The NIST Definition of Cloud Computing. NIST". National Institute of Standards and Technology (2011).

[5] Bob Liem Wilopo \& Wiwin Sulistyo. "Analisis Dan Implementasi Owncloud Sebagai Media Penyimpanan Pada Yayasan Salman Al-Farisi Yogyakarta". Universitas Kristen Satya Wacana(2016)

[6] Madhura Mulimani \& Rashmi Rachh. "Analysis of Access Control Methods in Cloud Computing" Visvesvaraya Technological University.(2017)

[7] Delvia Santi dkk "Implementasi Dan Analisis Performansi Raid Pada Data Storage Infrastructure As A Service (Iaas) Cloud Computing" Universitas Telkom (2013)

[8] Adison \& Eddy Prasetyo Nugroho. “Implementasi Cloud Computing Berbasis Iaas Dengan Membangun Private Storage Di Server Ubuntu Server 14.0 Menggunakan Owncloud". Universitas Pendidikan Indonesia Bandung (2015)

[9] Sumit Goyal. "Public vs Private vs Hybrid vs Community - Cloud. Computing: A Critical Review". Delhi (2014)

[10] Veranika Mei Aryani \& Fajar Suryawan. "Perancangan Server Dengan Memanfaatkan Proxmox Di Pengelola Data Elektronik Kabupaten Sragen". Universitas Muhammadiyah Surakarta (2014)

[11] Irfan Santiko dkk. "Pemanfaatan Private Cloud Storage Sebagai Media Penyimpanan Data E-Learning Pada Lembaga Pendidikan". STMIK AMIKOM Purwokerto (2017)

[12] Ibrahim, M., Kusnawi, "Analisis Dan Implementasi Owncloud Sebagai Media Penyimpanan Pada Yayasan Salman Al - Farisi Yogyakarta”, Jurnal Ilmiah DASI Vol. 14 No. 04 Desember 2013, hlm 32 - 37 ISSN: 14113201. (2013)

[13] W. Ono Purbo. 2012. Membuat Sendiri Cloud Computing Server Menggunakan Open Source. Yogyakarta : Penerbit Andi.

[14] Budiyanto, Alex. 2012. Pengantar Cloud Computing. Diunduh dari http://cloudindonesia.org

[15] Computer, Wahana. 2011. Kupas Tuntas Bermacam Aplikasi Generasi Cloud Computing. Yogyakarta: Penerbit Andi.
[16] Voorsluys, William; Broberg, James; Buyya, Rajkumar (February 2011). "Introduction to Cloud Computing". In R. Buyya, J. Broberg, A.Goscinski. Cloud Computing: Principles and Paradigms. New York, USA: Wiley Press 
